\title{
Guadamecíes del Archivo Histórico Provincial de León
}

\author{
Teresa Mํㅡㄹ ALORS BERSABÉ \\ Universidad de Córdoba
}

\begin{abstract}
Resumen. El Archivo Histórico Provincial de León posee una pequeña colección de piezas trabajadas en cuero compuesta por cuatro cubiertas de libro y doce guadamecíes, estas últimas de gran interés pues son pequeños fragmentos que, reutilizados probablemente como encuadernaciones, debieron formar parte en origen de una composición mayor destinada con toda certeza a decorar, a modo de tapiz, la estancia de alguna casa señorial. Mediante este artículo se pretende establecer una visión más clara de la fisonomía de estas pequeñas obras poniéndolas en relación con guadamecíes idénticos de otras colecciones cuyo estado de conservación es mucho mejor.

Palabras clave: Cuero, guadamecí, encuadernación, tapiz.

Abstract. Archivo Historico Provincial de Leon has a small collection of worked leather pieces, composed by four book covers and twelve interesting guadamecies, since they are fragments probably used as book covers but in the beginning they were part of a bigger piece, huge compositions whose function were to decorate, as a tapestry, rooms of the noble houses, improving their appearance. This article aims to establish a clearer vision of the physiognomy of these works, relating them to identical guadamecies from other collections that have been better preserved.

Key words: Leather, guadamecí, book-covers, tapestry.
\end{abstract}

El trabajo artístico del cuero en la Península Ibérica tuvo su origen en el siglo $X$, concretamente durante el Califato en la ciudad de Córdoba ${ }^{1}$. A partir de este momento el trabajo del guadamecí fue adquiriendo mayor importancia hasta convertirse en un elemento decorativo esencial en los hogares más distinguidos. Tras la reconquista cristiana ésta labor, en origen árabe, fue adoptada y readaptada a la nueva sociedad con un predominio inicial de moti9-10.

${ }^{1}$ T. LARraya, Cueros artísticos, Córdoba, 1956, pp. vos mudéjares, que con el paso del tiempo compartieron protagonismo con otras temáticas, como por ejemplo temas de carácter religioso. Esta labor en cuero no tardó en convertirse en un digno presente entre la aristocracia o como obsequio para reyes de otros países, para quienes dicha labor artesanal era algo original y novedoso ${ }^{2}$.

2 Juan II para conseguir la amistad del Rey de Francia y que éste le prestase ayuda contra los infantes de Aragón y la nobleza, [...] embióle muchos cueros de guadamecir e muchas alhombras, porque es cosa que en Francia no se han [...]" Cfr. Crónica del Señor Rey Don 
No obstante, aunque este tipo de trabajo se convirtió en una referencia esencial para España, no fue este país el que lo vio nacer, sino que vino importado desde el norte de África, concretamente desde una ciudad llamada Ghadames (Libia), región que dio su nombre a esta forma de trabajar el cuero, de ahí que se conozca como guadamecí o guadamacî́. Sin embargo, cuando la industria quedó asentada en la Península Ibérica, concretamente en la ciudad de Córdoba, el tipo de obraje varió considerablemente, pues mientras que en la región libia los cueros eran tintados, en los talleres cordobeses se comenzaron a dorar y policromar, generalmente con óleo, otorgándole a la pieza un valor estético añadido ${ }^{4}$.

Muchos autores han tratado sobre esta industria a lo largo de la historia ${ }^{5}$, exaltando la labor de estos artífices cuyos nombres van saliendo a la luz no sin dificultad, debido a la gran dispersión de los documentos y a la escasez de referencias que faciliten su búsqueda.

El guadamecí es una pieza de piel de carnero, conocida también con el nombre de badana, curtida en un primer tratamiento con zumaque, arbusto que debido a sus

Juan, segundo de ese nombre en Castilla y en León, compilada por el noble caballero Fernán Pérez de Guzmán, Valencia, 1779, p. 109.

${ }^{3} \mathrm{CH}$. Davillier, Notes sur les cuirs de Cordou, París, 1870, p. 5 .

${ }^{4}$ Ambrosio DE MORALES dejó testimonio de ello en su obra Las Antigüedades de España, Alcalá de Henares, 1575, p. 110: "Las badanas sirven para los guadamecis, que se labran tales en Cordova, que de ninguna parte de España ay competencia, y tantos, que á toda Europa y las Indias se provee de allí esta hazienda. Ella da a la ciudad mucha hazienda, y da también una hermosa vista por las principales calles della. Porque como sacan al sol los cueros dorados ya, labrados y pintados, fixados en grandes tablas, para que se enxuguen, haze un bel mirar aquello entapiçado con tanto resplandor y diversidad".

${ }^{5}$ Véase Al Maqqari, Thomaso Garzoni, Pedro de Medina, Méndez Silva, Ambrosio de Morales, Ch. Davillier o Rafael Ramírez de Arellano, entre otros. propiedades otorgaba calidad a la pieza. Este tipo de cuero era trabajado de forma cuidadosa empleando la policromía como rasgo fundamental de dicha labor, con lo que la pieza adquiría un valor pictórico interesante que la hacía mucho más atractiva para la ornamentación de interiores ${ }^{6}$.

No es de extrañar que fuera empleado también como frontales de altar, retablos o cuadros devocionales, donde el cuero no sólo funcionaba como un simple lienzo, sino que era trabajado con técnicas muy específicas diferenciándolo de la pintura tradicional. Este tipo de trabajo provocó la asociación de guadamecileros y pintores, que de forma conjunta abordaban encargos de gran índole 7 . Sin embargo, fue su función como tapiz la más demandada en la sociedad, convirtiéndose en el encargo más extendido durante el siglo XVI y principios del XVII, reflejando la moda del momento. Estos grandes tapices que decoraban paredes enteras se confeccionaban a partir de fragmentos menores de guadamecíes unidos entre sí mediante costuras. Tanto las medidas como la forma de coser quedaban recogidas en las Ordenanzas del gremio, estandarizándose de esta forma el proceso, hasta el punto de que la omisión de estas normas de elaboración tenían pena de multa:

"Iten que vayan las pieças muy bien regladas entiendese asy / la de la plata como de lo colorado porque de no yr bien reglados / hacen paños piernas e no asyentan en la pared e que I vengan todas las tiras de los dichos paños costuras con costuras / e que vayan muy bien cosydos y guarnesçidos.

\footnotetext{
${ }^{6}$ A. M. OCAÑA RIEGO, El cuero artístico cordobés, Córdoba, 2002, p. 15.

${ }^{7}$ A. URQUíZAR HERRERA, «Pintura y guadamecíes en la Córdoba del siglo XVI», Mil años del trabajo en cuero, Córdoba, 2003, pp. 510-532.
} 
Iten mandamos que la persona que qualquier de los capítulos suso / dichos quebrantare aya de pena por cada cuero mil mrs. re / partidos según dicho es [...] que todos sean de un tamaño las piezas / de dorado como de plata o de colorado y de otros cuales / quier colores que sean e han de tener el tamaño del molde / antiguo que es tres cuartas de vara de largo y dos tercias / menos una pulgada de ancho de los cual ha de haber dos moldes / fechos de hierro, sellados con el sello de la cibdad, uno en el ar / ca de los dichos oficiales que tengan dos llaves, la una esté en poder / del alcalde del oficio y la otra en poder del escribano del consejo, I el cual asimismo tenga otro molde, so pena que por cada paño de cualquier suerte que fuere que se hallare fecho I contra el proveido en este capítulo o contra cualquier parte / del haya y se lleve de pena al oficial seiscientos mrs. por cada paño [...] esta / ley sea general e igual para todos los oficiales del dicho / oficio que tiene ó tubiere tienda o lo usare en cualquier / manera, asi en esta cibdad como en otra cualquier parte que sea, / y demas de las dichas penas, que si se les faltare a los dichos / oficiales algunas piezas de menos tamaño de los que dicho es, / que, aunque no esté cosida en paño ni en otra cosa, caiga e incurra / por solo haberla fecho e tenerla en su poder en pena de cien mrs. por cada / pieza e la pieza perdida, todo aplicado como dicho es"8.

El primer paso para tapizar una estancia con guadamecíes consistía en tomar las medidas de la sala en conjunto y una vez obtenidas las mismas, se calculaba el número de piezas de guadamecí que serían necesarias para cubrir la sala, teniendo en cuenta las sobreventanas. A continuación se cosían entre sí de forma muy minuciosa, teniendo sumo cuidado de que las costuras

${ }^{8}$ Archivo Municipal de Córdoba (AMCO) Sección: Agricultura, industria y comercio. Serie: Industria, oficios y gremios. Documento: AH -06.02.25. C. 0191/001 Ordenanzas de guadamacileros de la ciudad de Córdoba del 1 de Enero de 1529. no se notasen, para que la composición final quedase encajada a modo de puzle ${ }^{9}$.

Córdoba, como se ha indicado anteriormente, fue la ciudad que acogió esta artesanía transformándola para adaptarla a la demanda de los ciudadanos. Debido al gran número de piezas exportadas a otras ciudades, pronto comenzaron a surgir talleres en otros centros que adquirieron gran importancia, tales como Madrid, Barcelona, Valencia y Valladolid entre otros, llegando incluso a traspasar fronteras siglos más tarde para asentarse en diversos puntos de Francia y los Países Bajos ${ }^{10}$.

Debido a la naturaleza orgánica del material son pocas las piezas que han llegado hasta nuestros días en comparación con la gran cantidad de encargos que se realizaron, más aún teniendo en cuenta que fue una artesanía vigente desde el siglo $X$ hasta el XVII, siendo el siglo XVI el periodo de mayor esplendor. A finales del XVII y sobre todo en el siglo XVIII el trabajo del guadamecí, aunque sobrevivía en algunas zonas como Madrid o Barcelona, comenzó a decaer hasta que finalmente desapareció a finales de dicho siglo, siendo sustituida por otras industrias que se pusieron de moda.

\section{EL GUADAMECÍ EN LA CIUDAD DE LEÓN}

La ciudad de León no fue un centro productor de guadamecíes, o al menos no hay constancia de que existieran talleres dedicados a dicha labor. Estudiando las ordenanzas del siglo XVI las únicas referencias que encontramos relacionadas con el trabajo del cuero son aquellas que se centran en la labor de los curtidores, artesanos

\footnotetext{
${ }^{9}$ J. FERRANDIS TORRES, «Guadamecíes», Discurso leído en su acto de recepción pública, Madrid, 1945, pp.4041.

${ }^{10}$ T. Larraya. Op. Cit. p. 14.
} 
estrechamente relacionados con la industria del calzado ${ }^{11}$. Sin embargo, existen otros datos o referencias que indican que el trabajo del guadamecí no sólo era conocido, sino que era muy apreciado como elemento decorativo.

A pesar de no producirlos, la ciudad de León posee un importante conjunto de piezas conservadas en el Museo de la Catedral de León y en el Archivo Provincial Histórico de la ciudad -cuyo análisis se abordará en este estudio-, y dentro de la provincia son dignas de mención las nueve piezas que posee el Museo de la Catedral de Astorga.

\section{CUEROS DEL ARCHIVO HISTÓRICO PROVINCIAL DE LEÓN.}

El Archivo Histórico Provincial de León posee un total de dieciséis piezas de cuero trabajado. Cuatro de ellas corresponden a cubiertas de libros realizadas ex profeso, mientras que las doce restantes son fragmentos de guadamecíes pertenecientes a composiciones mayores que fueron posiblemente reutilizados como cubiertas de libros. La hipótesis de este reaprovechamiento se basa en la existencia de otras piezas completas localizadas en diversas colecciones que presentan el mismo tipo de decoración o en algunos casos el mismo esquema ornamental, evidenciando que esos fragmentos son en realidad parte de una composición mayor posiblemente destinada a la decoración de interiores.

Las cuatro primeras piezas, correspondientes a las encuadernaciones que fueron elaboradas con esa intención, presentan unas composiciones muy comunes y generalizadas durante el siglo XVI, respondiendo a esquemas compositivos muy sim-

${ }^{11}$ Véase la publicación de las Ordenanzas de León, León, 1996, pp. 130-143. ples. Atendiendo al diseño decorativo, una de ellas podría encuadrarse dentro de lo que se conoce como encuadernaciones protorrenacentistas $^{12}$ (Fig. 1). Parece tratarse de piel de becerro, uno de los materiales más empleados en esta etapa, cuya ornamentación se desarrolla a partir de cenefas, empleando la rueda con motivos vegetales, hojas y flores de gran tamaño que se van combinando con medallones que albergan bustos masculinos -uominis famosi- colocados de perfil. El empleo de la rueda hace que los motivos ornamentales formen una especie de orla rectangular que encierra otra idéntica de menor tamaño, la cual a su vez sirve de encuadre a los elementos vegetales que se sitúan en el centro de la encuadernación, elaborados esta vez con hierros sueltos creando pequeñas hojas triformes en los ángulos, y otras dos que enmarcan el florón central cruciforme de mayores dimensiones, todo ello desarrollado de forma simétrica. La composición queda rematada con una serie de líneas rectas, conocidas como filetes, que la rodean creando formas rectangulares y triangulares.

Otra de las encuadernaciones, también renacentista, es mucho más sencilla respecto a su ornamentación, pues se compone de una sola cenefa decorada con elementos vegetales enlazados entre sí, posiblemente tallos ondulados que se desarrollan de forma simétrica. Por desgracia, la decoración se aprecia con cierta dificultad debido al mal estado en el que se encuentra la pieza. La técnica empleada en este caso sería de nuevo la rueda, esta vez mucho más sencilla, completada del mismo modo con el uso de filetes rectangulares. La cenefa principal crea un espacio central en el que sólo se aprecia un elemento vegetal, un

${ }^{12}$ Existen numerosos catálogos de encuadernaciones en los que se recogen ejemplares similares, véase, por ejemplo, Encuadernaciones artísticas en las Colecciones Municipales, Madrid, 1994, p.35 
florón cruciforme realizado, como en el anterior caso, con hierro suelto. Muestra un desgaste cerca de la flor, cuyo motivo se desconoce y que podría ser testimonio de una antigua decoración.

Una tercera encuadernación, de la misma época, está ornamentada únicamente con molduras o canalillos simples -los ya citados filetes- que forman motivos geométricos, acompañados por un pequeño friso de roleos en la parte superior. Esta ornamentación simple hace que la pieza tenga un escaso valor estético.

Estos tres ejemplares, junto a un cuarto que carece de decoración, son encuadernaciones elaboradas con este fin específico, es decir, piezas en cuero que protegían el contenido y al mismo tiempo le otorgaban un carácter estético. Por otro lado, las doce piezas restantes que posee el Archivo son fragmentos de guadamecíes, que pasaron de ser grandes paneles decorativos a pequeñas piezas recortadas posiblemente destinadas a proteger ciertos documentos o libros a modo de encuadernación. Esta es la idea que se defiende tras el hallazgo de restos de hojas escritas que aún pueden verse en el reverso de algunas de estas piezas de guadamecí. El motivo de que estas piezas fuesen reutilizadas se desconoce, ni siquiera se ha podido constatar el tipo de documento que albergaban estas cubiertas. Por el contrario, sí se ha podido averiguar la fisonomía de la pieza en origen, pues se han conservado en diversas colecciones paneles de guadamecíes con el mismo diseño ornamental, de las que se sabe con certeza que fueron empleados como paneles decorativos, que tan demandados fueron durante el siglo XVI para la decoración de las estancias de las casas nobles.

Estos fragmentos muestran diversos esquemas decorativos, tales como elementos vegetales, molduras mixtilíneas, moti- vos geométricos y animales fantásticos. Todos ellos presentan un rasgo en común, el empleo de motivos que permiten realizar composiciones de grandes dimensiones sin perder la armonía de la forma. Lo curioso de estas piezas que se conservan en el Archivo y que las hacen tan interesantes radica en la posible reutilización de las mismas con otra función totalmente diferente.

Cuatro de estas piezas de guadamecí siguen el mismo modelo ornamental (Fig. 2). Se trata de una decoración muy sencilla, la cual consta de dos molduras desarrolladas de forma simétrica, a modo de roleo, en cuyo interior encierra un ramillete de flores, todo ello enmarcado a ambos lados por un pequeño friso de elementos geométricos. Estas piezas han perdido parte de la policromía, conservando sólo algunas zonas donde se aprecia cierta tonalidad granate, empleándose el negro para perfilar el contorno de los motivos vegetales. Por el contrario, el trabajo del ferreteado -motivos grabados por medio de hierros o cinceles que eran golpeados sobre la pieza quedando impreso el motivo decorativo ${ }^{13}$ - se aprecia con claridad tanto en el interior de las molduras, donde se crea un dibujo circular, como en el friso en el que se usa el rayado creando una forma compacta. Atendiendo tanto al tipo de decoración como a la técnica empleada esta pieza puede datarse en el siglo XVI. Este mismo esquema compositivo se desarrolla de forma idéntica en otros guadamecíes conservados en distintas colecciones, lo que permite ver con claridad la idea que se está planteando. Entre los muchos conservados, se tomará como muestra una pieza de colección particular, la cual funcionó en su origen como friso de una composición mayor, cuya ornamentación es exacta a las cuatro piezas del Archivo (Fig.

${ }^{13}$ J. FERnÁNDEZ MÁRQUEZ, Arte de labrar los guadamecíes y cueros de Córdoba, Córdoba, 1953, pp. 98-99. 
3) ${ }^{14}$. La pieza del catálogo está compuesta por varios fragmentos unidos entre sí de forma cuidadosa mediante costuras, apreciándose esa continuidad en las líneas que permite ampliar la composición sin que la armonía del esquema ornamental quede rota o confusa. Es por ello por lo que con toda certeza la pieza del Archivo pudo ser en origen parte de una cenefa.

Quizás uno de los ejemplos más interesantes que posee el Archivo Histórico Provincial de León es aquél en el que aparece un tema muy común durante el siglo XVI y que fue empleado como friso completando composiciones decorativas mucho más extensas (Fig. 4). La pieza leonesa está bastante deteriorada, puesto que falta gran parte de la composición original. No obstante, el fragmento permite contemplar parte de la estructura de la composición, formada por dos hipocampos alados que flanquean un jarrón central con flores y frutos. En este guadamecí se trabaja sobre todo la pintura, estando las figuras realizadas a trazo negro sobre un fondo verde que aún mantiene su color. Normalmente, los guadamecíes que centran su labor en la policromía van acompañados por un minucioso trabajo de ferreteado, pues es la forma de añadir un valor estético frente a la ausencia de otras técnicas como por ejemplo el repujado, muy común en estos trabajos en cuero. Los ferretes adquieren un papel fundamental, utilizando de forma abundante los círculos concéntricos de diversos tamaños en parte de los grifos y el jarrón, completado con un rayado en todas direcciones que se desarrolla con un mismo fin: formar una masa compacta a partir de pequeñas figuras repetidas y unidas entre sí. Este mismo tema, aunque con ciertas variantes en cuanto a la calidad de la manufactura, se puede encontrar en numerosas

14 J. FERRANDIS TORRES. Cordobanes y guadamecies, Madrid, 1955, p. 100. piezas de diversas colecciones, entre las que se citarán dos ubicadas en Córdoba. Una de ellas, perteneciente al Excmo. Ayuntamiento de Córdoba, sólo presenta la parte correspondiente al friso, compuesta por los dos grifos rampantes situados a ambos lados de un jarrón central (Fig. 5), mientras que la otra ${ }^{15}$ se trata de un panel completo de grandes dimensiones que permite imaginar cómo eran aquellas piezas que antaño cubrían las paredes de las habitaciones de esas casas aristocráticas (Fig. 6). Esta última está formada por tres temas diferentes; por un lado, los grifos rampantes estarían funcionando como una cenefa superior, encuadrando parte del panel central, debiendo duplicarse el fragmento para poder abarcar la longitud de la decoración de fondo. La diferencia entre ésta y la pieza del Archivo Histórico Provincial de León radica principalmente en la calidad de la obra, puesto que en la pieza cordobesa se puede apreciar trazos mucho más complejos definiendo con más detalle las figuras de los animales fantásticos ${ }^{16}$, así como el jarrón central, que está mucho más elaborado decorado con pequeñas molduras; en definitiva, se trata de una composición mucho más cuidada. El resto de la pieza está formado por columnas abalaustradas, ampliamente difundidas a partir de las Medidas del Romano de Diego de Sagredo ${ }^{17}$, encuadrando las tres cuartas partes restantes de la decoración central. Finalmente, la parte central de la composición está decorada mediante elementos vegetales entrelazados con molduras que se desarrollan de forma simétrica en todas direcciones, demostrando de nuevo cómo

${ }^{15}$ Pieza perteneciente a la colección del Museo del Palacio del Marqués de Viana en Córdoba. Cfr. J. FERRANDIS TORRES, Op. Cit., Lám. XX

${ }^{16}$ Véase el minucioso trabajo de las alas del grifo o la cabeza, mucho más elaborada.

${ }^{17}$ D. DE SAGredo, Medidas del Romano, 1541. Asimismo eran muy comunes este tipo de columnas en los frontispicios de los códices miniados. 
era común el empleo de motivos ornamentales que pudieran repetirse fácilmente sin perder el ritmo de la composición. Observando las tres piezas se aprecia que la calidad de la manufactura es muy dispar, pues mientras que la pieza de León es mucho más sencilla en el dibujo, las piezas cordobesas son mucho más elaboradas, no obstante, se parte de la misma idea. Como se ha indicado, en el siglo XVI esta temática fue muy común y prueba de ello es que no sólo existen piezas idénticas en Córdoba y León sino también en el Museo Episcopal de Vich y en el Museo de Artes Decorativas de Madrid ${ }^{18}$.

Otro motivo decorativo que tuvo su origen en el siglo XVI y que continuó con éxito durante el siglo XVII fue la combinación de molduras de diversas formas y de elementos vegetales, muchas veces entrelazados creándose así composiciones bastante más complejas. Algunas de las piezas del Archivo de León, que podrían datarse en el siglo XVII, presentan este esquema, en el que empleanse molduras mixtilíneas de cierto grosor decoradas en su interior, alternándose con distintos elementos vegetales. La estructura tuvo que ser en origen una composición mucho mayor, como prueban los cortes sufridos posteriormente que rompen totalmente la simetría de la misma. Dos de las piezas que posee el Archivo leonés, una conservada mejor que la otra, están tan fragmentadas que difícilmente se podría imaginar cómo hubieran sido en origen sin contar con una pieza de mayores dimensiones con la que poder hacer un análisis comparativo (Fig. 7). Afortunadamente, existe un panel de guadamecí en el Museo Episcopal de Vich que sigue el mismo diseño compositivo y que conserva la estructura en su totalidad (Fig. 8) ${ }^{19}$. La

\footnotetext{
18 J. FERRANDIS TORRES, Op. Cit. p. 99.

${ }^{19}$ Ibid, p. 102.
}

pieza catalana presenta estas mismas molduras con pequeñas variaciones que radican en la decoración, donde se aprecia un interesante juego de claroscuro. Estas molduras crean una forma cerrada en cuyo interior aparecen elementos vegetales, concretamente una flor de cardo de la que emergen una serie de hojas que quedan repartidas por el fondo ${ }^{20}$. En los ángulos, fuera de la moldura, aparecen otras hojas que al unirse formarían otro cardo, creando así una composición simétrica que podía ampliarse ajustándose a cualquier espacio.

Las molduras empleadas para la decoración de guadamecíes podían ser de muy diversos tipos, desde la compuesta por una sola franja, hasta las más complejas de formas quebradas con decoración interna. Todo era válido para realizar estos grandes paneles, siendo la única regla el empleo de figuras que pudieran repetirse simétricamente. Si antes se ha aludido a molduras que poseían su propia decoración, ahora se analizará aquellas otras molduras formadas por simples líneas curvas que se alternan con elementos vegetales. Existen tres piezas en el Archivo de León que presentan este tipo de temática. Una de ellas, bastante mal conservada, muestra este tipo de línea ondulada que se alternaba con elementos vegetales, concretamente hojas anchas poco definidas (Fig. 9). No obstante, lo que sí se ha conservado bastante bien es el trabajo del ferreteado, empleando círculos concéntricos que otorgan a la pieza gran plasticidad, así como el rayado. Curiosamente, la policromía también se aprecia con cierta

\footnotetext{
${ }^{20}$ La flor de cardo plasmada en la obra no parece algo extraño, pues la decoración vegetal era un motivo ornamental muy común en el trabajo artístico del cuero en siglos anteriores. Pero teniendo en cuenta el lugar en el que se encuentra esta obra - Museo Episcopal de Vich - quizá pueda relacionarse con la Casa de Cardona, la más poderosa de toda la corona de Aragón, cuyo título se remonta al siglo VIII y cuyas armas presentan tres flores de cardo idénticas.
} 
claridad, siendo el dorado el gran protagonista. Los otros dos fragmentos están decorados con especies de molduras curvas, que bien pudiera tratarse de algún elemento vegetal a modo de tallo, encerrando ciertas figuras inidentificables debido al estado de conservación (Fig. 10). Sin embargo, al igual que en el caso anterior, se aprecia con claridad el trabajo del ferreteado y la policromía de la misma, utilizando ferretes de círculos concéntricos y rayados, junto a una policromía mixta combinando el dorado con tonos granates.

Por otro lado, los elementos vegetales adquirieron un gran protagonismo en los guadamecíes que iban a ser empelados como tapices, aunque también predominaron en los frontales de altar como un elemento decorativo más ${ }^{21}$. Este tipo de ornamentación fue muy demandando para la decoración de las estancias debido a que hubo una tendencia muy extendida que consistía en transformar espacios interiores en verdaderos jardines porticados, evocando así a la propia naturaleza, para lo que se empleaba una tonalidad alegre donde los colores vivos, verdes, granates, azules, etc., se combinaban otorgando a la estancia una rica policromía. Debido a que con el paso del tiempo los colores perdían fuerza, a consecuencia de las propiedades del cuero que tiende a ennegrecer paulatinamente, esta policromía se completaba con tonos dorados y plateados que otorgaban luminosidad al espacio. Es así como las hojas, flores o incluso animales predominaban en estas composiciones. El Archivo Histórico posee dos fragmentos que tienen como protagonistas diversos motivos vegetales (Fig. 11). Ambos presentan el mismo esquema decorativo: composiciones muy simples en las que aparecen como fondo unas pequeñas hojas, algunas con tonos

${ }^{21}$ M. Nieto CUMPLido, Cordobanes y guadamecíes de Córdoba, 1979, pp.19-22. verdes, entre las que surgían flores rojas muy esquematizadas que se repiten durante toda la superficie de forma idéntica. Cuentan además con una cenefa floral también muy sencilla que aún mantiene parte de su color. Con toda certeza este tipo de obra formaría parte de una composición mayor, posiblemente un panel decorativo a modo de zócalo, y aunque no se conocen ejemplos idénticos como en los casos anteriores que permitan ver cómo sería en origen, sí existen composiciones similares que se desarrollaron de forma abundante durante los siglos XVI y XVII. El reverso de esta pieza es muy interesante puesto que presenta restos de cierto documento, siendo la prueba a partir de la cual se planeta la hipótesis de que estas piezas pudieron ser reutilizadas como encuadernaciones (Fig. 12).

Mediante este estudio se ha pretendido mostrar cómo a partir de pequeños fragmentos, que en principio pueden parecer de escaso valor, se puede obtener una información muy significativa. El estudio de los guadamecíes es a veces bastante complicado, ya que se trata de un material que sufre mucho ante las inclemencias del tiempo, lo que unido al hecho de que en siglos anteriores cuando una pieza de estas características se deterioraba era más fácil sustituirla por una nueva que restaurarla, hace que cualquier fragmento, por pequeño que sea, se convierta en una fuente imprescindible de información para su estudio, para el análisis de modelos o morfología que permite entender no sólo rasgos de la pieza en sí, sino que también refleja aquellos gustos de la sociedad que en cada época demandaba este tipo de obras. 


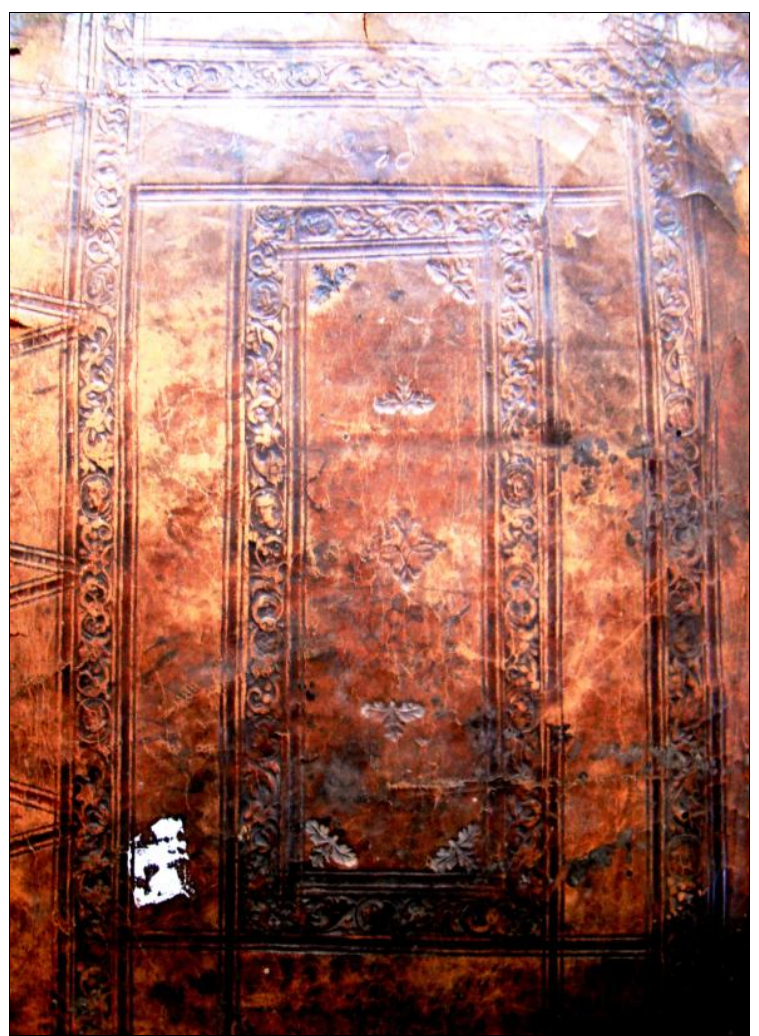

- Fig. 1. Encuadernación protorrenacentista, s. XVI (España. Junta de Castilla y León. AHPLe. Fondo: Colecciones. Guadamecíes. CE. ZP.)

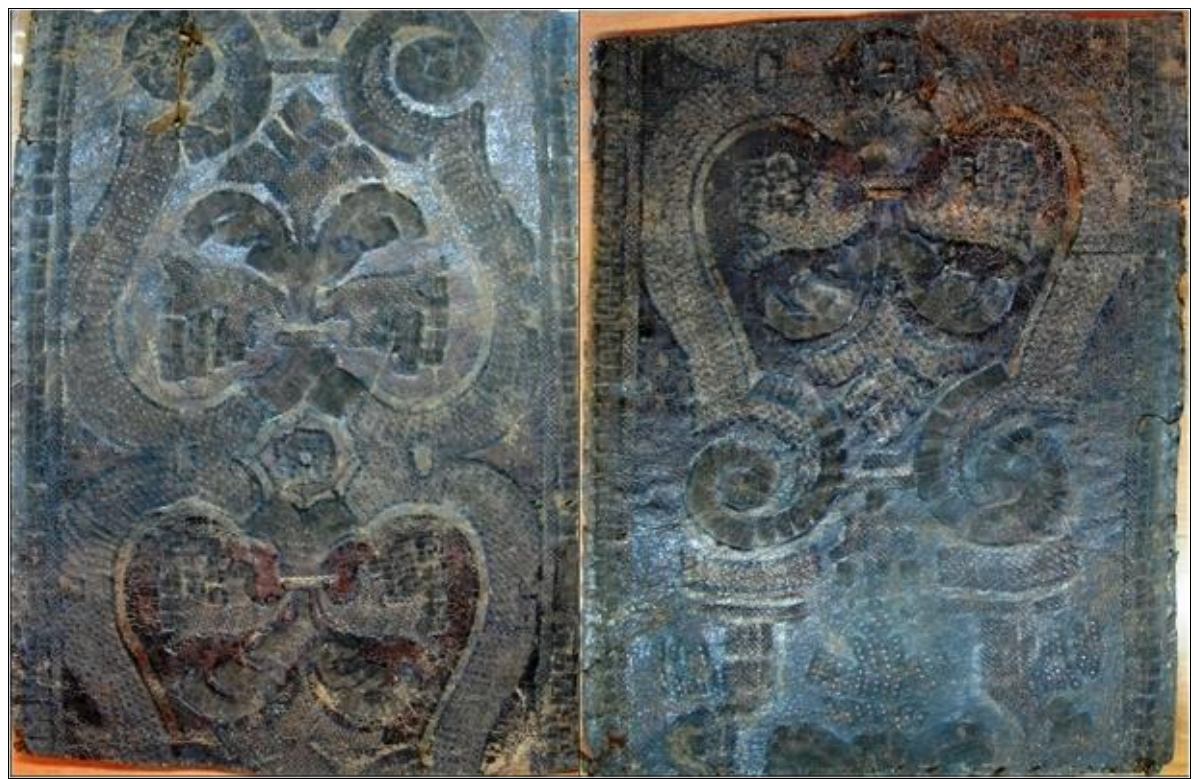

- Fig. 2. Fragmentos de guadamecí con molduras onduladas y decoración vegetal, s. XVI (España. Junta de Castilla y León. AHPLe. Fondo: Colecciones. Guadamecíes. CE. ZP.) 


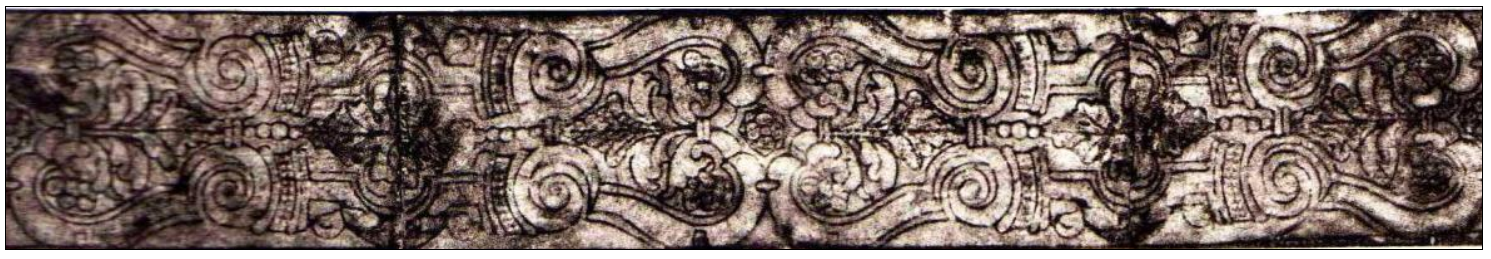

- Fig. 3. Friso de guadamecí con molduras onduladas y decoración vegetal. S. XVI. Colección particular (Fuente: J. FERRANDIS TORRES, Cordobanes y guadamecíes, Madrid, 1955, Lám. XXV)

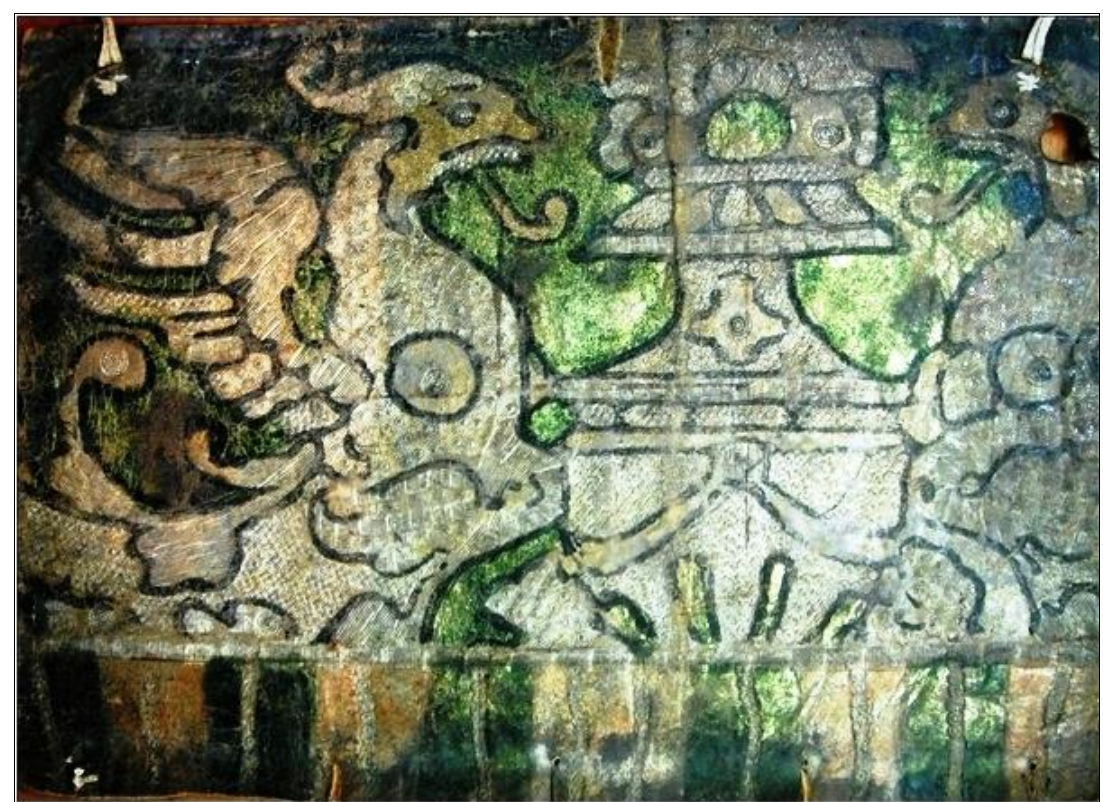

- Fig. 4. Fragmento de guadamecí con hipocampos alados y jarrón central, siglo XVI (España. Junta de Castilla y León. AHPLe. Fondo: Colecciones. Guadamecíes. CE. ZP.)

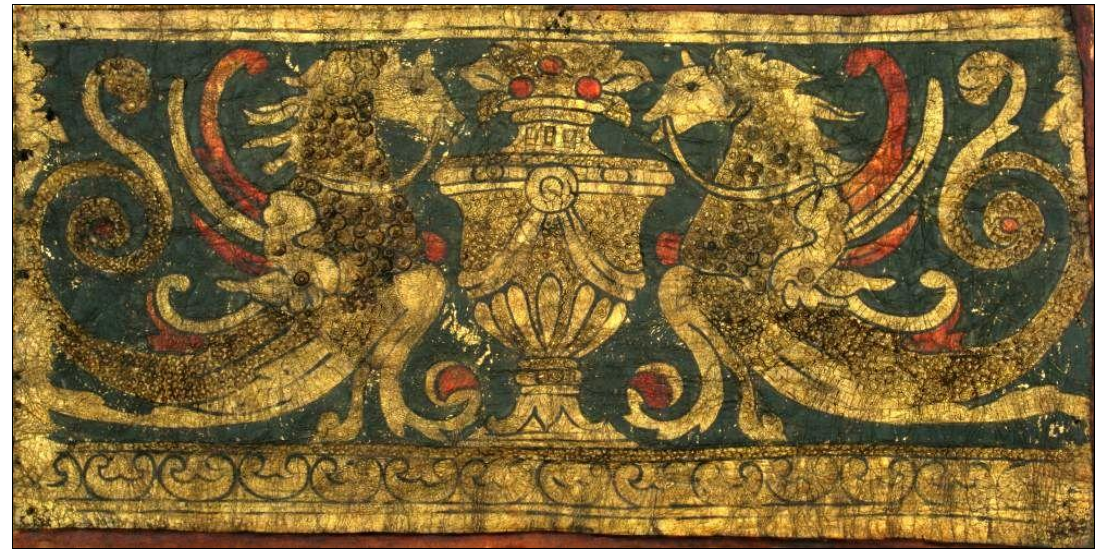

- Fig. 5. Guadamecí de hipocampos, en piel de carnero, siglo XVI, 46,50 x $22,50 \mathrm{~cm}$ (Colecciones de cordobanes y guadamecíes. Excmo. Ayuntamiento de Córdoba) 


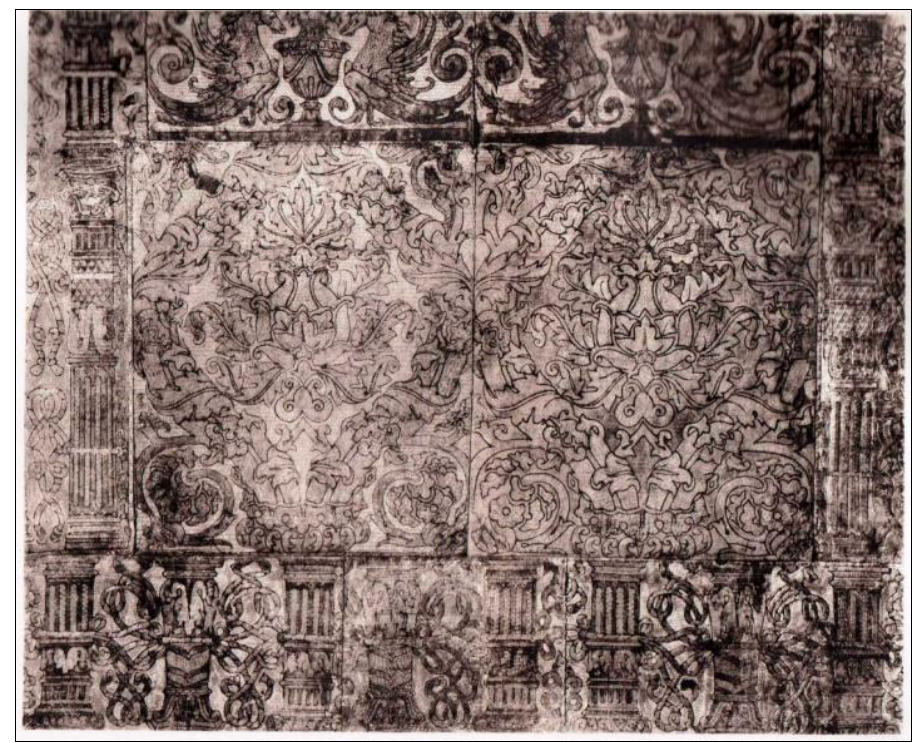

- Fig. 6. Panel de guadamecí, siglo XVI. Palacio-Museo de los Marqueses de Viana, Córdoba (Fuente: J. FERRANDIs TORRES, Cordobanes y guadamecíes, Madrid, 1955, Lám. XX)
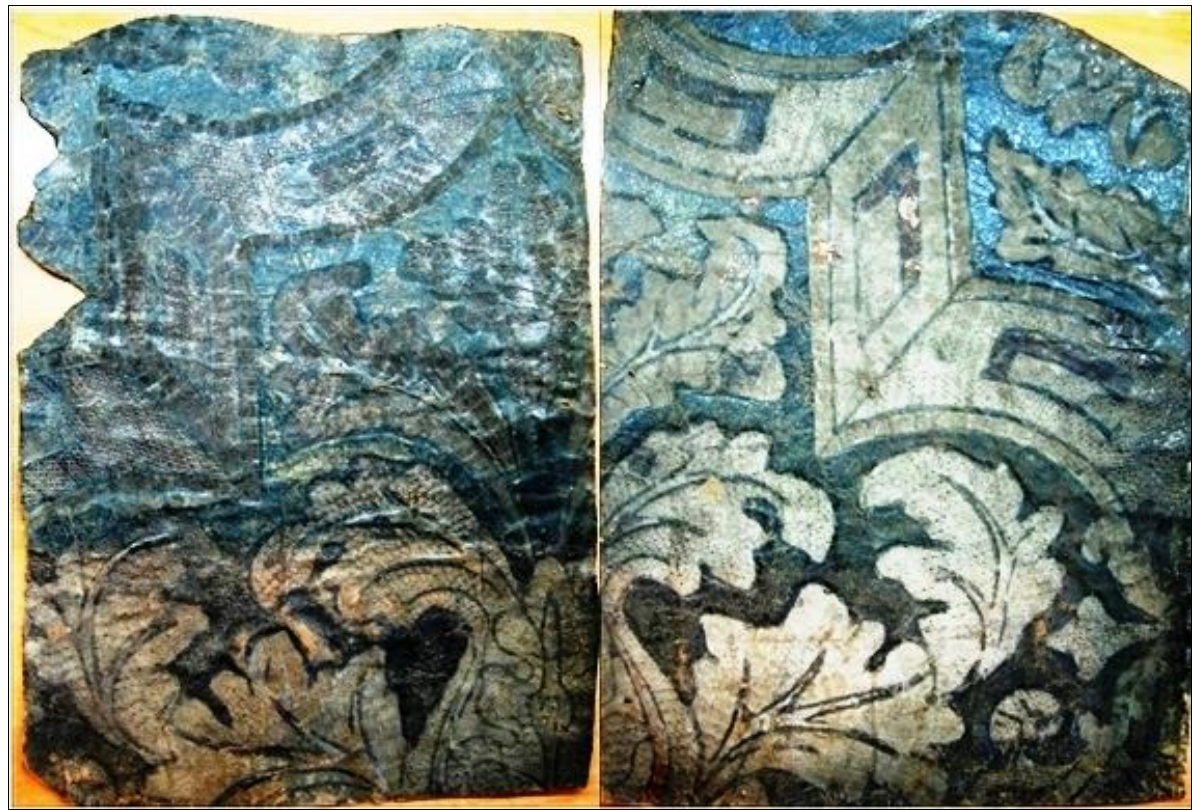

- Fig. 7. Fragmentos de guadamecí con molduras mixtilíneas y flor de cardo, siglo XVII (España. Junta de Castilla y León. AHPLe. Fondo: Colecciones. Guadamecíes. CE. ZP.) 


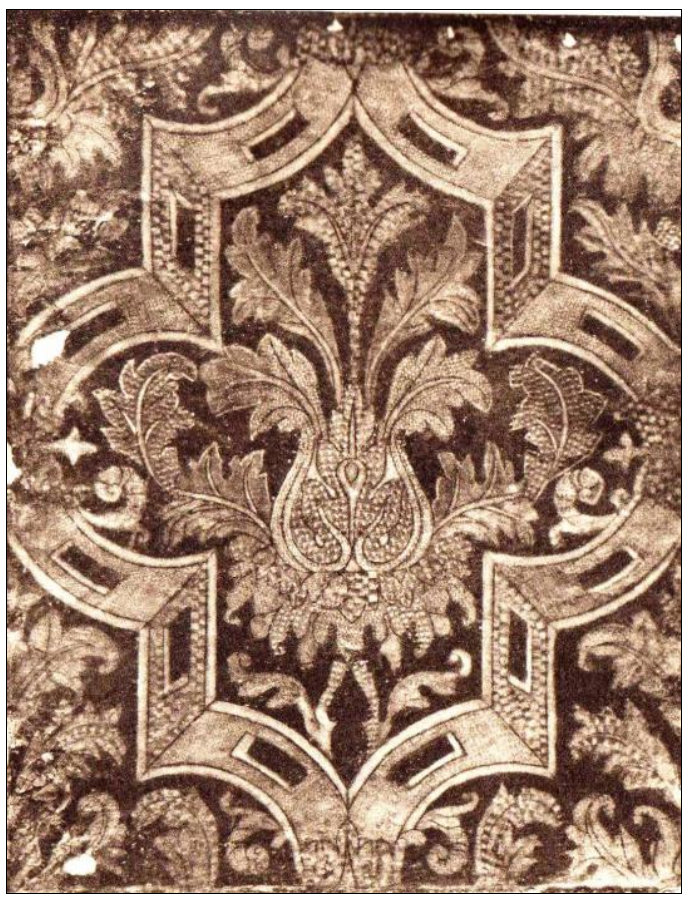

- Fig. 8. Panel de guadamecí con moldura mixtilínea y flor de cardo, siglo XVII. Colección Particular (Fuente: J. FERRANDIS TORRES, Cordobanes y guadamecíes, Madrid, 1955, Lám. $\mathrm{XXX)}$

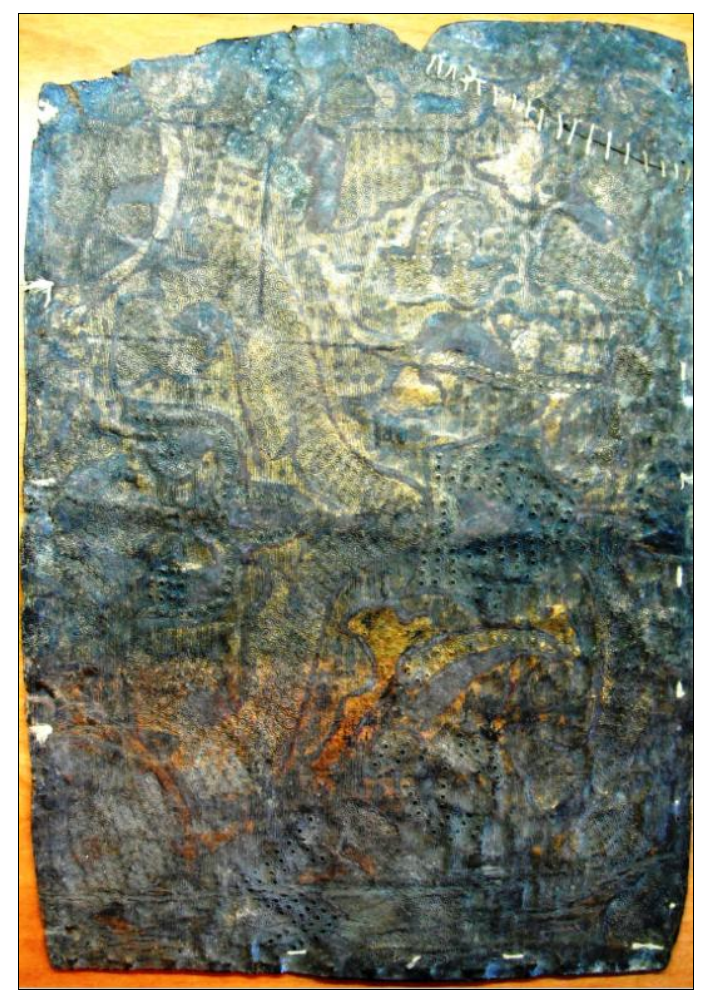

- Fig. 9. Fragmento de guadamecí con molduras onduladas y elementos vegetales, siglo XVI (España. Junta de Castilla y León. AHPLe. Fondo: Colecciones. Guadamecies. CE. ZP.) 


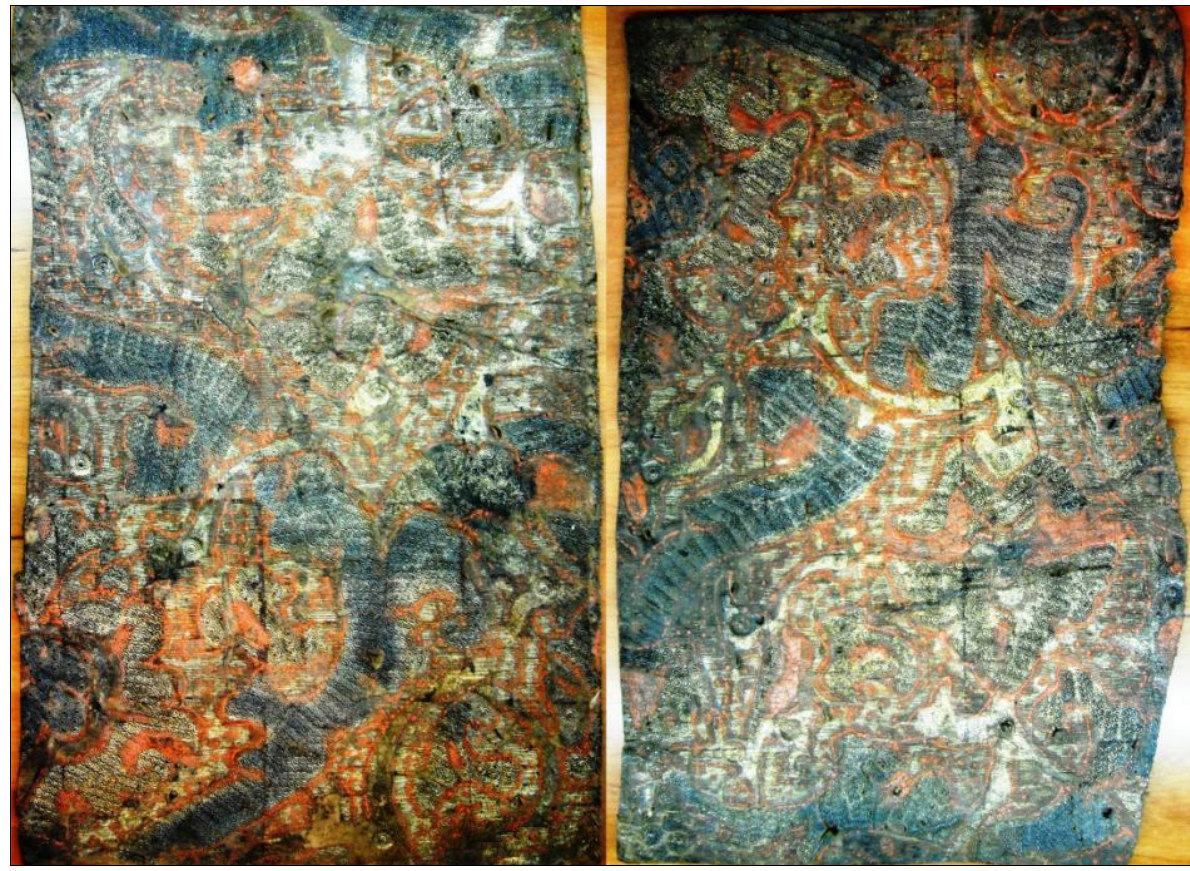

- Fig. 10. Dos fragmentos de guadamecí con molduras onduladas y elementos esquemáticos, siglo XVI (España. Junta de Castilla y León. AHPLe. Fondo: Colecciones. Guadamecíes. CE. ZP.)
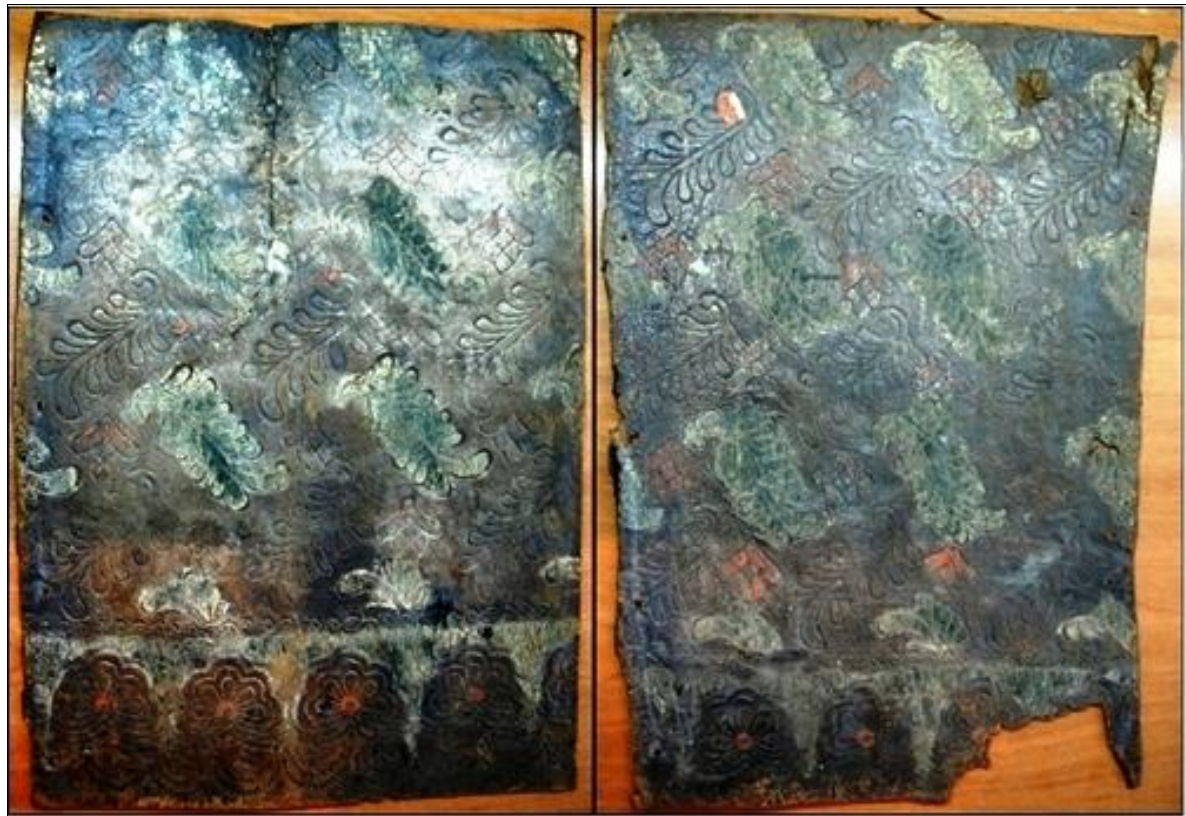

- Fig. 11. Fragmentos de guadamecí con elementos vegetales -hojas y flores muy esquematizadas-, posiblemente siglo XVI (España. Junta de Castilla y León. AHPLe. Fondo: Colecciones. Guadamecíes. CE. ZP.) 


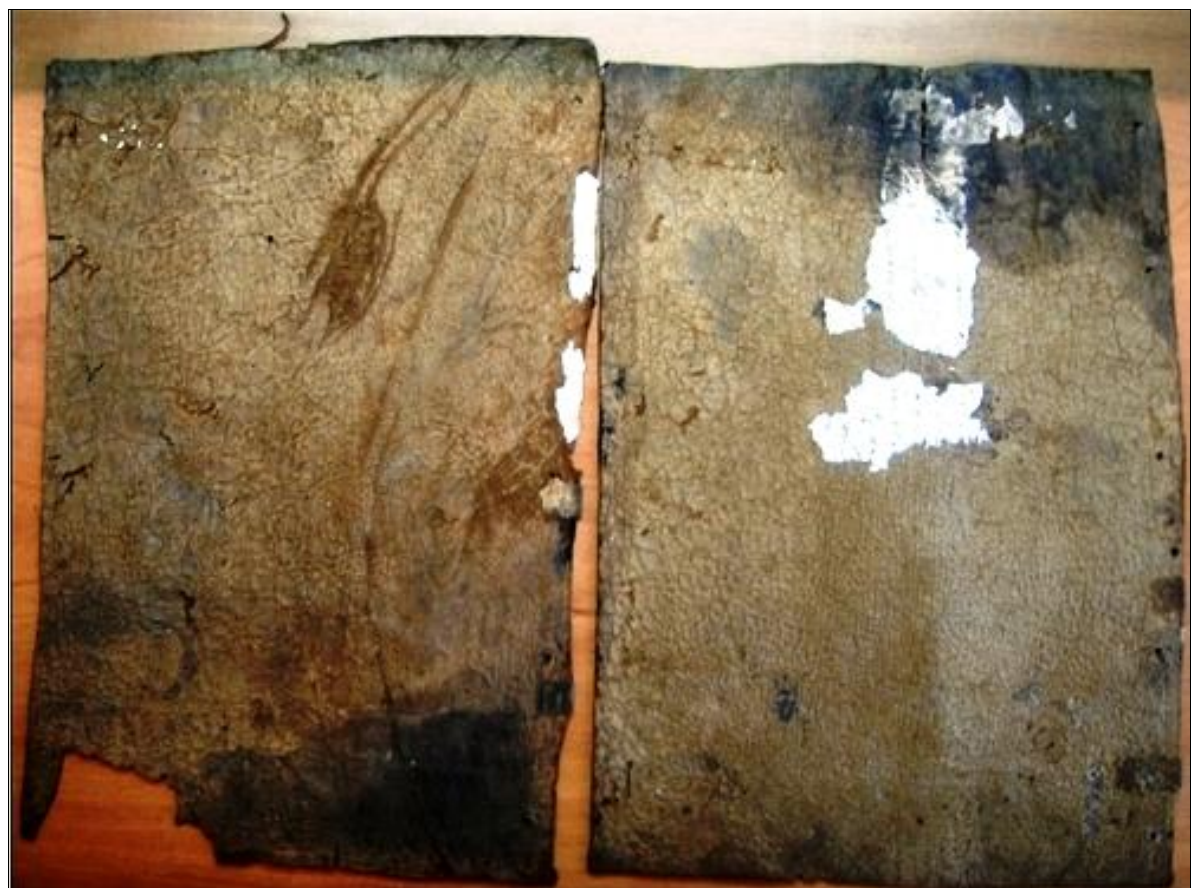

- Fig. 12. Reverso de la pieza anterior -Fig. 11- dónde aún quedan restos de papel escrito (España. Junta de Castilla y León. AHPLe. Fondo: Colecciones. Guadamecíes. CE. ZP.) 